Polymer Journal, Vol. 39, No. 7, pp. 722-730 (2007)

(C) 2007 The Society of Polymer Science, Japan

\title{
Crystallization Behavior of Polypropylene Filled with Modified Carbon Black
}

\author{
Jing Chen, Xianhui LI, and Chifei $\mathrm{WU}^{\dagger}$ \\ Polymer Alloy Laboratory, School of Materials Science and Engineering, East China University of Science and Technology, \\ 130 Meilong-lu, Shanghai 200237. P. R. China
}

(Received July 31, 2006; Accepted April 9, 2007; Published May 29, 2007)

\begin{abstract}
A novel method was employed to modify the surface of carbon black (CB) by organic small molecules in a Haake Rheomix mixer. The investigations of Thermo Gravimetric Analysis (TGA), transmission electron microscopy (TEM), Flourier Transform Infrared spectroscopy (FT-IR) and X-ray Photoelectronic Spectroscopy (XPS) indicated that organic small molecules were grafted onto the surface of MCB and the particle size of MCB was reduced notably. Then the crystallization behavior of polypropylene (PP)/MCB composite as well as pure PP and $\mathrm{PP} / \mathrm{CB}$ composite were investigated via differential scanning calorimeter (DSC), wide angle X-ray diffraction (WAXD) and optical polarizing microscope (POM). It was found that both $\mathrm{CB}$ and $\mathrm{MCB}$ can influence the crystallization behavior of $\mathrm{PP}$ and provide nucleation sites to the matrix. However, $\mathrm{MCB}$ accelerated the crystallization rate and increased the crystallization peak temperature of PP more evidently than CB did. In the case of non-isothermal crystallization, Jeziorny and Mo Equations were used to analyze the data of DSC and both could describe these systems. Finally, the nucleation activity of MCB was evaluated. It was proved that the nucleation activity of MCB was higher than that of $\mathrm{CB}$ at the same concentration. [doi:10.1295/polymj.PJ2006084]

KEY WORDS Carbon black / Polypropylene / Composite / Crystallization / Nucleation /
\end{abstract}

It is well known that PP is a general plastic with a higher consumption due to their well-balanced physical and mechanical properties and easy process ability, but PP shows unsatisfactory impact strength at low temperatures because of its large spherulites. Several methods have been adopted in industry practice to overcome the shortcoming of PP. One of the important methods is adding nucleating agents. ${ }^{1,2}$ Application of nucleating agents can improve the crystalline temperature, increase the crystallinity and accelerate the crystallization rate. Usually, nucleating agents can be classified as organic and inorganic. There are lots of researches that focus on PP crystallization via organic nucleating agents, and also a few hundred publications about inorganic nucleating agents, such as glass fiber, ${ }^{3}$ calcium carbonate $\left(\mathrm{CaCO}_{3}\right),{ }^{4}$ silicon dioxide $\left(\mathrm{SiO}_{2}\right),{ }^{5}$ talc, ${ }^{6}$ zinc oxide $(\mathrm{ZnO})^{7}$ and clay, ${ }^{8}$ but little has been reported using $\mathrm{CB}$ as a nucleating agent. ${ }^{9,10}$

$\mathrm{CB}$ is one of the industrially important and commercially available carbon materials, which has excellent properties, such as heat, chemical and weather resistance, light weight, electro-conductivity, and low thermal expansion. In general, reducing the particle size of CB and dispersing it uniformly in polymer matrix are very difficult because of aggregation of the powder. To improve its dispersibility and control its particle size, the chemical and physical modifications of the surface of $\mathrm{CB}$ have been extensively investigated. ${ }^{11-13}$ But these methods are not efficient and not suitable to be applied industrially. Furthermore, the structure of $\mathrm{CB}$ cannot be controlled by these methods, namely the aggregates of $\mathrm{CB}$ cannot be broken down.

In this paper, a novel method is employed to modify the surface of CB by organic small molecules. The aggregates of $\mathrm{CB}$ are broken down and the interface between $\mathrm{CB}$ and $\mathrm{PP}$ is modified during the blending process. $\mathrm{CB}$ is known to have the free radicals on its surface, ${ }^{14}$ and the organic small molecule chosen is a phenolic antioxidant whose phenolic hydroxyl and ester groups can form the strongest interactions with $\mathrm{CB} .{ }^{15}$ Gutzow et al. ${ }^{16,17}$ developed a theory to explain why inorganic particles nucleate crystallization in linear polyolefins. Nucleation efficiency is related to the bond energies between the nucleating agent and the polymeric crystals. The organic small molecules wrapping on the surface of $\mathrm{CB}$ can increase the interaction between the fillers and the matrix. Moreover, fillers with small particle size and narrow size distribution can lead to much higher nucleation densities in the matrix. Tang et al. ${ }^{7}$ observed an increase in the nucleation densities when the particle size of $\mathrm{ZnO}$ is below $100 \mathrm{~nm}$ and nano $\mathrm{ZnO}$ as a nucleating agent is more efficient than micro $\mathrm{ZnO}$. It can be presumed that if the particle size of MCB had de-

${ }^{\dagger}$ To whom correspondence should be addressed (Tel: +86-21-64252569, Fax: +86-21-64252569, E-mail: Wucf@ecust.edu.cn). 
Crystallization Behavior of PP Filled with Modified CB

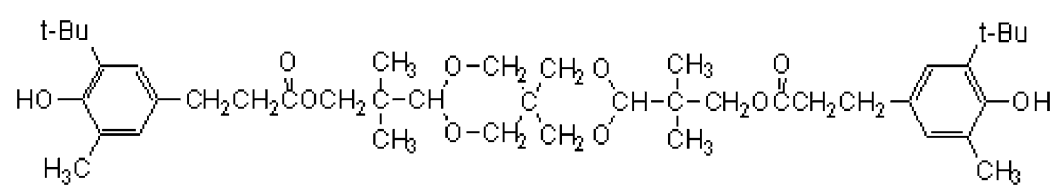

Scheme 1.

creased to the nanoscale size, it would be more efficient.

The objectives of this investigation were to concentrate on the crystallization behavior of the $\mathrm{PP} / \mathrm{MCB}$ composite. The results were compared with those of pure $\mathrm{PP}$ and $\mathrm{PP} / \mathrm{CB}$ composite. The actual processing is preformed under non-isothermal conditions, so the non-isothermal crystallization kinetics of the PP/ MCB composite were measured and analyzed by means of Jeziorny and Mo equations. The nucleation activity of the $\mathrm{PP} / \mathrm{CB}$ and $\mathrm{PP} / \mathrm{MCB}$ composites during non-isothermal crystallization were also evaluated.

\section{EXPERIMENTAL}

\section{Materials}

A commercially available grade of polypropylene (isotactic homopolymer, $M_{\mathrm{n}}=80000, M_{\mathrm{w}}=$ 333000 and $\mathrm{MFI}=3.00 \mathrm{~g} / 10 \mathrm{~min}$ ) used in this paper is T300, supplied by Sinopec Shanghai Petrochemical Co. of China. A special grade of CB, whose primary particle size is about to $20 \mathrm{~nm}$ and DBP is $114 \mathrm{~mL} /$ $100 \mathrm{~g}$, was kindly supplied by Shanghai Li Shi Chemical Industry and Commerce Corp. A hindered phenol compound, called AO-80, whose melting point is $125^{\circ} \mathrm{C}$, was kindly provided by Asahi Denka Co. Ltd. Its structural formula is shown in Scheme 1.

\section{Sample Preparation}

MCB were prepared in a Haake Rheomix mixer (Haake Rheomix600p, Germany), equipped with a pair of high shear roller-type rotors with a volume of $3 \mathrm{~cm}^{3}$. The weight ratio of $\mathrm{CB}$ and $\mathrm{AO}-80$ is 1:0.8. The temperature of the mixing chamber was set at $140^{\circ} \mathrm{C}$ and the blending time was $30 \mathrm{~min}$. The rotor rate was $60 \mathrm{rpm}$. The mixed sample was extracted by acetone for $72 \mathrm{~h}$ in a soxhlet apparatus and then dried for use.

The composites were also prepared in a Haake Rheomix internal mixer at $180^{\circ} \mathrm{C}$ for $15 \mathrm{~min}$. The rotor rate was $60 \mathrm{rpm}$. Once PP was molten, the appropriate percentage of filler was added. The obtained samples were pressed at $200{ }^{\circ} \mathrm{C}$ for 10 min under a pressure of $10 \mathrm{MPa}$ and cooled at ambient temperature. Specimens of about $0.5 \mathrm{~mm}$ in thickness were cut from the plaques for the various measurements. The $\mathrm{PP} / \mathrm{MCB}$ composites are donated $\mathrm{PP} / \mathrm{x} \% \mathrm{MCB}$, where $\mathrm{x} \%$ refers to the weight fraction of $\mathrm{MCB}$ in the composite. The pure PP and $\mathrm{PP} / \mathrm{CB}$ composite were prepared by the same method for the purpose of comparison.

\section{Characterization of $M C B$}

The micrographs of $\mathrm{CB}$ and $\mathrm{MCB}$ were obtained from a JEM-1200EXII TEM operated at an accelerating voltage of $60 \mathrm{KV}$ at ambient temperature. MCB and $\mathrm{CB}$ were dispersed in ethanol in an ultrasonic bath for $10 \mathrm{~min}$, then were mounted on 200-mesh copper grids and dried in a desiccator before the TEM observation. The concentration of $\mathrm{CB}$ and $\mathrm{MCB}$ solutions is $2.5 \mathrm{~g} / \mathrm{L}$.

Thermal Gravimetric Analyzer (TA SDT Q600 V5.0 Build 63) was used to characterize the weight loss of organic small molecules on the surface of $\mathrm{CB}$ from room temperature to $800^{\circ} \mathrm{C}$ at the scan rate of $10^{\circ} \mathrm{C} / \mathrm{min}$ under a dry nitrogen purge.

The FT-IR spectrum of MCB was carried out on Nicolet AVATAR360 in the diffuse reflection mode. The sample used in experiment was mixture of $\mathrm{MCB}$ and dried $\mathrm{KBr}\left(3 \mathrm{~h}\right.$ at $\left.300^{\circ} \mathrm{C}\right)$, employing the blending of $\mathrm{CB}$ and $\mathrm{KBr}$ as control.

The XPS spectra of MCB and CB were obtained using a VG Scientific ESCA LAB MK-II spectrometer (VG ScientificEast Grinstead, UK), equipped with a $\mathrm{Mg} \mathrm{K} \alpha \mathrm{X}$-ray source. The X-ray power was $300 \mathrm{~W}$, and the spot size was approximately $1 \mathrm{~cm}^{2}$. The electron flood gun was set at $6 \mathrm{eV}$. The vacuum in the analysis chamber was lower than $10^{-7} \mathrm{~Pa}$.

\section{Morphological Observation}

The crystalline morphology of pure PP and its composites was studied on the films using an optical polarizing microscope equipped with a Mettler FP-82HT automatic hot-stage thermal control. Samples were melted and squeezed between a microscope cover glass at $200{ }^{\circ} \mathrm{C}$ for $5 \mathrm{~min}$ and then cooled at ambient temperature for observing.

\section{Thermal Analysis}

A NETZSCH DSC 200 PC was used for investigations of the crystallization behavior. Calibration was performed using pure indium at a heating rate of $10^{\circ} \mathrm{C} / \mathrm{min}$. The standard procedure performed in non-isothermal scans was as follows: samples of about $6 \mathrm{mg}$ were heated from the room temperature 


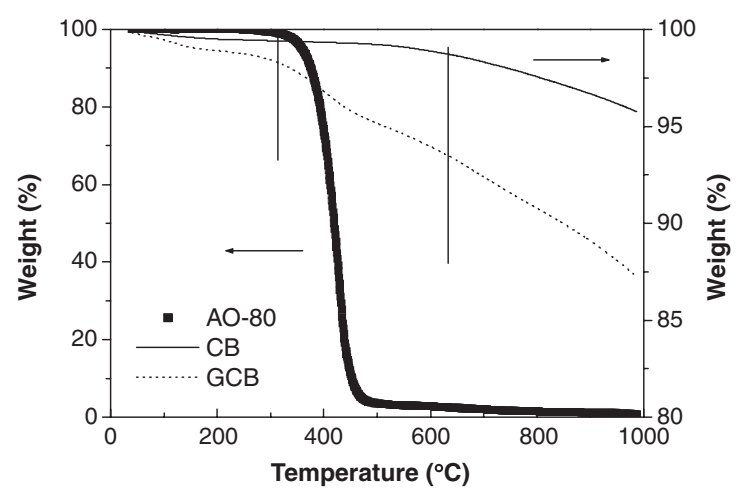

Figure 1. TGA curves for AO-80, CB and MCB.

to $200^{\circ} \mathrm{C}$ at the scan rate of $10{ }^{\circ} \mathrm{C} / \mathrm{min}$ and held for 5 min to diminish the influence of thermal and mechanical history. The samples were non-isothermally crystallized from $200^{\circ} \mathrm{C}$ to $80^{\circ} \mathrm{C}$ at different cooling rates from 1 to $10^{\circ} \mathrm{C} / \mathrm{min}$. The whole process was protected by a nitrogen atmosphere.

\section{WAXD Analysis}

WAXD was used to characterize the composites' crystalline structure. WAXD patterns were collected using a Rigaku D/max $2550 \mathrm{VB} / \mathrm{PC}$ diffractometer at the wave length of $\lambda C u K \alpha_{1}=1.54 \AA$, a tube voltage of $40 \mathrm{KV}$ and tube current of $100 \mathrm{~mA}$.

\section{RESULTS AND DISCUSSION}

\section{Characterization of $M C B$}

The TEM micrographs of MCB and CB are shown in Figure 1. It is observed that MCB is separated from each other, while $\mathrm{CB}$ is agglomerated together. The results reveal that the aggregates of $\mathrm{CB}$ are broken down by the shearing force and MCB has a smaller particle size than $\mathrm{CB}$ does.

Figure 2 shows the weight loss of AO-80, CB and MCB. The progress of pyrolysis can be classed into three steps. In the second step, the weight of AO-80 decreases markedly in a narrow temperature range of $350-450{ }^{\circ} \mathrm{C}$ with a maximum at $410^{\circ} \mathrm{C}$. At the same temperature range, the weight loss of MCB also decreases drastically, because of the weight loss of AO-80 on the surface of MCB. However, the weight loss of $\mathrm{CB}$ is far smaller than that of MCB. The results confirm that AO-80 can form strong interaction with the surface of $\mathrm{CB}$ and MCB can act as filler for many thermoplastics, because most processing temperatures are below $400^{\circ} \mathrm{C}$.

The FT-IR has been used to analyze the interaction between CB and stabilizer. ${ }^{15}$ In this research, FT-IR was carried out in the diffuse reflection mode, and the sample used in experiment was mixture of $\mathrm{MCB}$ and dried $\mathrm{KBr}$, employing the blending of $\mathrm{CB}$ and
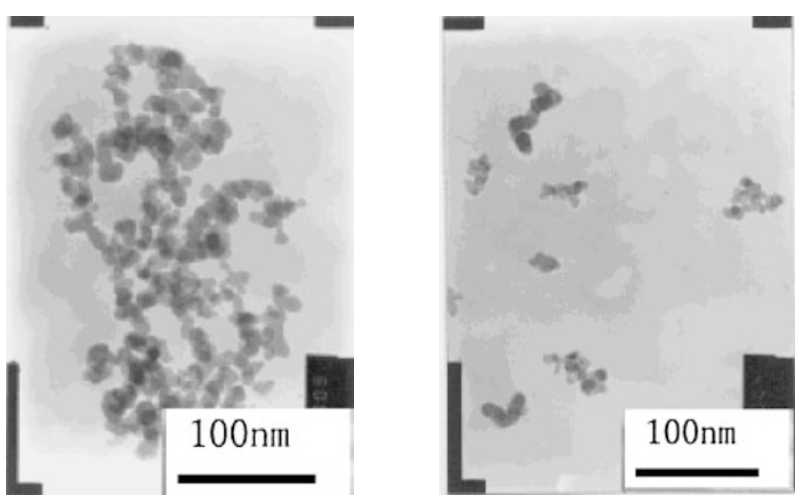

Figure 2. TEM micrographs at $50 \mathrm{~K} \times$ magnification for (a) $\mathrm{CB}$ and (b) $\mathrm{MCB}$.

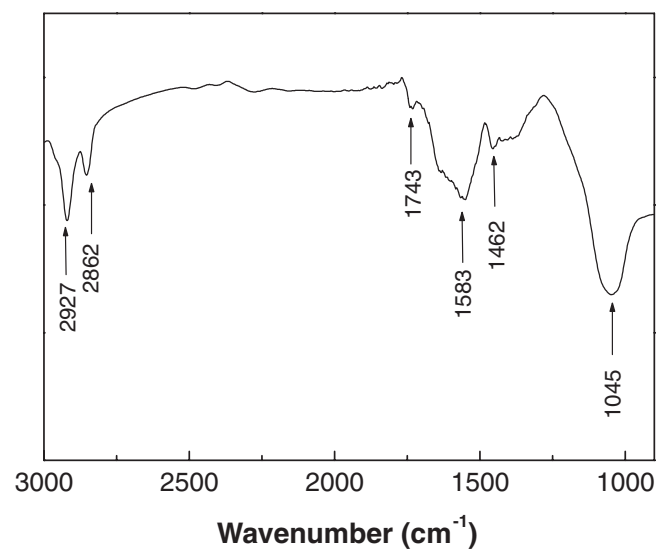

Figure 3. FT-IR spectra of MCB in diffuse reflection mode.

dried $\mathrm{KBr}$ as control. Figure 3 shows the FT-IR spectrum MCB with AO-80. In the FT-IR spectra, it is observed these absorbing peaks: $2927 \mathrm{~cm}^{-1}$ and 2862 $\mathrm{cm}^{-1}$ are assigned to the $\mathrm{C}-\mathrm{H}$ stretching vibrations of $\mathrm{CH}_{3}$ and $\mathrm{CH}_{2}, 1583 \mathrm{~cm}^{-1}$ is assigned to aromatic structure, $1045 \mathrm{~cm}^{-1}$ belongs to the vibrations of $\mathrm{C}-$ $\mathrm{O}$, and $1743 \mathrm{~cm}^{-1}$ belongs to the vibrations of $\mathrm{C}=\mathrm{O}$. All these results detected by FT-IR indicated that the molecules of AO- 80 are grafted onto the surface of $\mathrm{CB}$ since the free molecules of AO- 80 are removed absolutely.

The surface properties of $\mathrm{CB}$ are usually investigated employing XPS. ${ }^{18}$ The high-resolution $\mathrm{C}_{1 \mathrm{~S}}$ XPS spectra of $\mathrm{CB}$ and $\mathrm{MCB}$ are presented in Figure 4. The $\mathrm{C}_{1 \mathrm{~S}}$ spectra of $\mathrm{CB}$ reveals the presence of four peaks, corresponding to $\mathrm{C}-\mathrm{C}$ groups $(284.5 \mathrm{eV}), \mathrm{C}-$ $\mathrm{O}$ groups $(286.0 \mathrm{eV}), \mathrm{C}=\mathrm{O}$ groups $(287.5 \mathrm{eV})$ and $\mathrm{COOH}$ groups $(289.1 \mathrm{eV})$. Compared to that of $\mathrm{CB}$, the $\mathrm{C}_{1 \mathrm{~S}}$ spectra of MCB shifts to higher binding ener$\mathrm{gy}$, and also shows four peaks, corresponding to $\mathrm{C}-\mathrm{C}$ groups $(285.4 \mathrm{eV}), \mathrm{C}-\mathrm{O}$ groups $(286.0 \mathrm{eV}), \mathrm{C}=\mathrm{O}$ groups $(287.2 \mathrm{eV})$ and $\mathrm{COOH}$ groups $(289.8 \mathrm{eV})$. It is known that the binding energy of $\mathrm{C}_{1 \mathrm{~S}}$ in aliphatic $\mathrm{C}-\mathrm{C}$ groups is located at $285.4 \mathrm{eV}$. That means that 


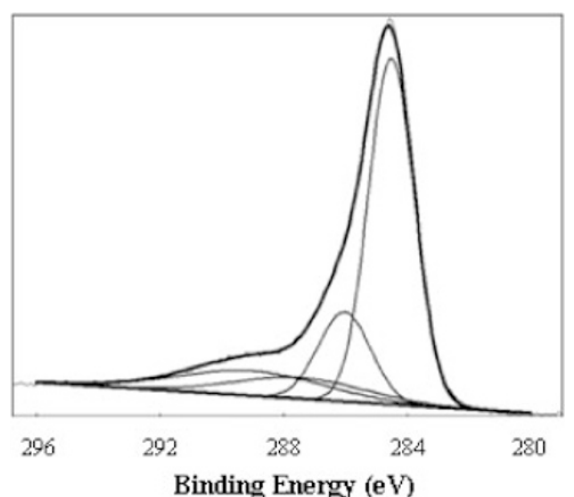

(a) $\mathrm{CB}$

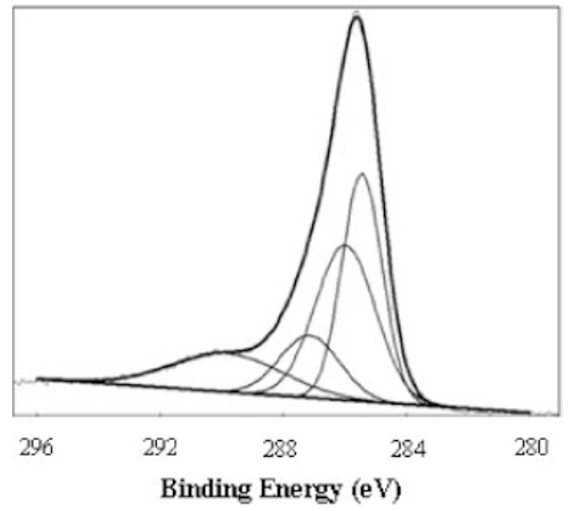

(b) $\mathrm{MCB}$

Figure 4. High-resolution $\mathrm{C}_{1 \mathrm{~s}}$ XPS spectra of (a) CB and (b) MCB.

there are aliphatic chains on the surface of MCB, i.e., AO-80.

Combined with the results of the TGA, FT-IR, TEM and XPS, it can conclude that the aggregates of MCB are broken up, due to the powerful shear force, and at the same time, their surfaces are grafted by melting organic small molecules, and thus they can not get together again. Next work will focus on the grafting mechanism of MCB by organic small molecules.

\section{Melting Behavior}

In the case of semicrystalline polymers, it is known that the crystallization behavior get affected by the presence of particulate additives especially at low concentrations. The changes can affect the overall properties of the material, so the crystallization behavior of PP was studied under the presence or absence of MCB.

The DSC melting traces of pure PP and its composites are presented in Figure 5. For pure PP, two melting peaks are observed, one at $152.5^{\circ} \mathrm{C}$ and the other at $167.8^{\circ} \mathrm{C}$. It was reported ${ }^{19-21}$ that there are two different crystallographic forms of pure PP: an unstable pseudohexagonal $\beta$ form of lower melting point and

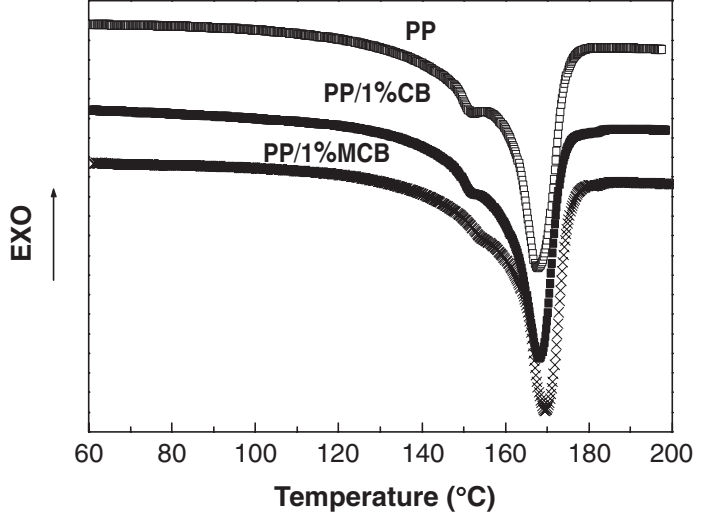

Figure 5. DSC melting curves for pure PP and its composites at a heating rate of $10^{\circ} \mathrm{C} / \mathrm{min}$.

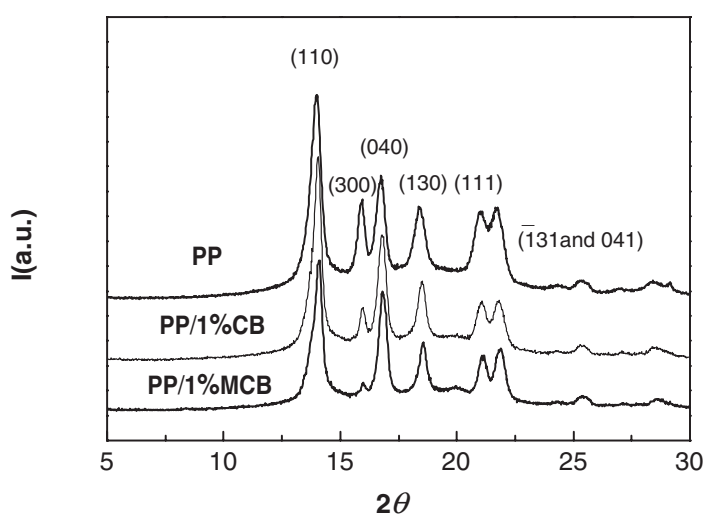

Figure 6. Ambient temperature X-ray diffractograms for pure $\mathrm{PP}$ and its composites.

lower perfection, and a more stable monoclinic $\alpha$ form of higher ordering and higher melting point. The later WAXD results confirm the existence of $\beta$ form crystals in pure PP. The same tendency is also observed for the $\mathrm{PP} / 1 \% \mathrm{CB}$ and $\mathrm{PP} / 1 \% \mathrm{MCB}$ composites. However, the melting peak of $\beta$ form becomes weak with the addition of $\mathrm{CB}$ and $\mathrm{MCB}$ and that of the $\mathrm{PP} /$ $1 \% \mathrm{CB}$ composite is the weakest, illustrating that MCB appears as the nucleus of PP crystallization in the $\alpha$ form more efficiently than CB does.

\section{WAXD Analysis}

To find out the exact crystalline structure of pure PP and its composites, WAXD measurement was performed. PP can crystallize in four polymorphic components: in the $\alpha, \beta$ forms and more rarely in the $\gamma$ and $\delta$ forms. ${ }^{22}$ The monoclinic $\alpha$ form of PP yields reflections at the following Bragg scattering angles, that is $2 \theta$, and corresponding Miller indices: $14.1^{\circ}$ (110), $16.8^{\circ}$ (040), $18.6^{\circ}$ (130), $21.1^{\circ}$ (111), $21.8^{\circ}$ (131 and 041). The hexagonal $\beta$ form of PP exhibits the following reflections and corresponding Miller indices: $2 \theta=16.1^{\circ}(300)$ and $21.1^{\circ}(301) .{ }^{23}$ The dif- 
Table I. The $\beta$ phase concentration in the crystalline part of pure PP and its composites

\begin{tabular}{cccc}
\hline Samples & $\mathrm{PP}$ & $\mathrm{PP} / 1 \% \mathrm{CB}$ & $\mathrm{PP} / 1 \% \mathrm{MCB}$ \\
\hline$\beta$ form concentration & $14.8 \%$ & $6.5 \%$ & $2.1 \%$ \\
\hline
\end{tabular}

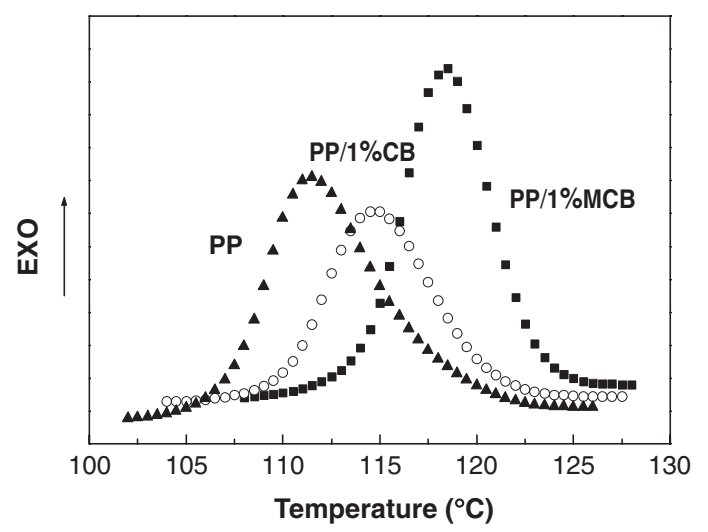

Figure 7. DSC cooling curves of pure $\mathrm{PP}$ and its composites after cooling from melt at a cooling rate of $10^{\circ} \mathrm{C} / \mathrm{min}$.

fractograms in Figure 6 indicates the presence of the $\beta$ form of in pure PP via reflections at $2 \theta=16.1^{\circ}$ (300) and $21.1^{\circ}$ (301). When adding $1 \mathrm{wt} \% \mathrm{MCB}$ in the matrix, there is a slight increase in the relative intensities of the $(h k l)$ reflections, a decrease in the amorphous contribution and a better separation between the (111) reflection and the reflections of (1)31 and 041).

The $\beta$ form fraction can be assessed from the ratio of the height of the main (300) $\beta$ reflection to the sum of the heights of the four main crystalline reflections, i.e. (110), (040) and (130) from the $\alpha$ form plus (300) from the $\beta$ form, as proposed by A. T. Joners et al. ${ }^{24}$ The various reflection heights were determined after subtraction of the amorphous halo. This $\beta /(\alpha+\beta)$ ratio is designated in the text as the $\beta$ form concentration. The results are shown in the Table I. It appears that MCB induces a larger fraction of PP to crystallize in the $\alpha$ form than CB does, which is consistent with the conclusion of thermal analysis. However, Mucha et al. ${ }^{9}$ has observed that $\mathrm{CB}$ appears as the nucleus of PP crystallization in the $\beta$ form, which is different from ours. In our study, neither $\mathrm{CB}$ nor $\mathrm{MCB}$ as a nucleating agent can lead to the nucleation of the $\beta$ crystal form.

\section{Crystallization Behavior}

Figure 7 shows the DSC curves of non-isothermal crystallization for pure PP and its composites at a cooling rate of $10^{\circ} \mathrm{C} / \mathrm{min}$. It is obvious that addition of $\mathrm{CB}$ can improve the crystalline temperature from $111.4^{\circ} \mathrm{C}$ to $114.7^{\circ} \mathrm{C}$, and further to $118.3^{\circ} \mathrm{C}$ with addition of MCB. The crystallization peak temperature
Table II. Non-isothermal crystallization kinetics parameters for pure PP and its composites

\begin{tabular}{ccccc}
\hline Samples & $\Delta H_{\mathrm{c}}(\mathrm{J} / \mathrm{g})$ & $T_{\mathrm{o}}\left({ }^{\circ} \mathrm{C}\right)^{1)}$ & $T_{\mathrm{p}}\left({ }^{\circ} \mathrm{C}\right)^{2)}$ & $X_{\mathrm{c}}(\%)$ \\
\hline PP & 96.3 & 117.9 & 111.4 & 54.1 \\
$\mathrm{PP} / 1 \% \mathrm{CB}$ & 76.5 & 120.6 & 114.7 & 43.4 \\
$\mathrm{PP} / 1 \% \mathrm{MCB}$ & 101.8 & 122.8 & 118.3 & 57.8 \\
\hline
\end{tabular}

1): $T_{\mathrm{o}}$ is the temperature at which the spontaneous crystallization has occurred. 2): $T_{\mathrm{p}}$ is the crystallization peak temperature.

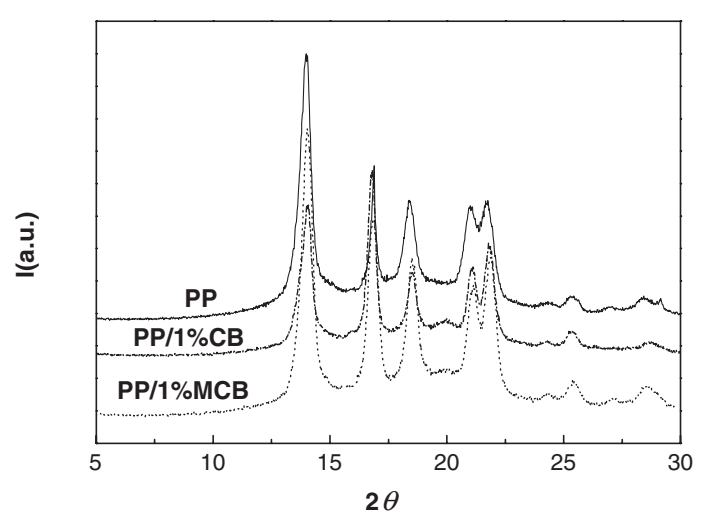

Figure 8. Ambient temperature $\mathrm{X}$-ray diffractograms for pure $\mathrm{PP}$ and its composites after cooling from melt at a cooling rate $10^{\circ} \mathrm{C} / \mathrm{min}$.

$\left(T_{\mathrm{p}}\right)$, the onset temperature $\left(T_{\mathrm{o}}\right)$ and other crystallization parameters for the samples are summarized in Table II. According to S. Piccarolo, ${ }^{25}$ when the cooling rate is below $10^{\circ} \mathrm{C} / \mathrm{s}$, only $\alpha$ form is present. From Figure 8, the (300) $\beta$ reflections for pure PP, $\mathrm{PP} / 1 \% \mathrm{CB}$ and $\mathrm{PP} / 1 \% \mathrm{MCB}$ composites are not observed, which conform that there is only $\alpha$ form in the matrix. The crystallinity $\left(X_{\mathrm{c}}\right)$ after this non-isothermal crystallization can be determined with eq 1 :

$$
X_{\mathrm{c}}=\frac{\Delta H_{\mathrm{c}}}{(1-\phi) \Delta H_{\mathrm{m}}} \times 100
$$

where $\Delta H_{\mathrm{c}}$ is the apparent enthalpy of crystallization and $\Delta H_{\mathrm{m}}$ is the enthalpy corresponding to the melting of a $100 \%$ crystalline isotactic PP. $\Delta H_{\mathrm{m}}$ of $\alpha$-PP is $178 \mathrm{~J} / \mathrm{g}^{26}$ and $\phi$ is the weight fraction of the filler in the composite.

The results demonstrate that $T_{\mathrm{o}}$ and $T_{\mathrm{p}}$ of the PP/ $1 \% \mathrm{CB}$ and $\mathrm{PP} / 1 \% \mathrm{MCB}$ composites move toward the higher temperature than those of pure PP. Further, those of the latter increase more markedly. It is apparent that the addition of only $1 \mathrm{wt} \% \mathrm{MCB}$ can nucleate $\mathrm{PP}$ crystal growth and accelerate its crystallization rate more evidently. At the same concentration, $\mathrm{MCB}$ increases the crystallinity of PP, as opposed to CB. We suppose that the increase of the crystallinity of PP in the presence of MCB might be caused by a com- 


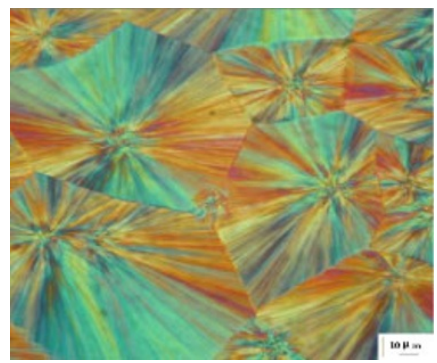

(a) PP

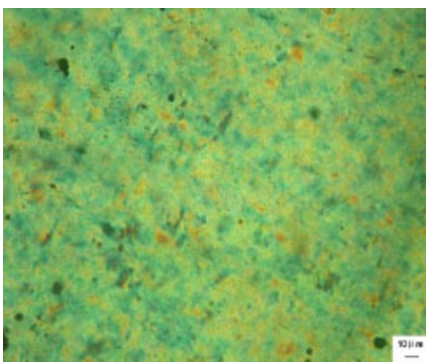

(b) $\mathrm{PP} / 1 \% \mathrm{CB}$

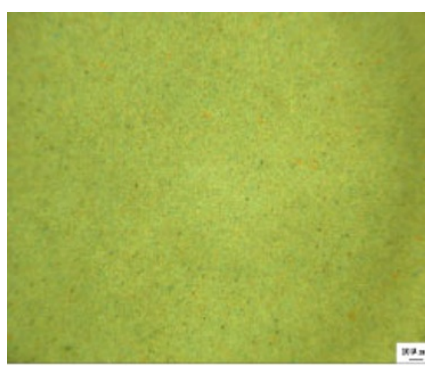

(c) $\mathrm{PP} / 1 \% \mathrm{MCB}$

Figure 9. Microphotographs for pure $\mathrm{PP}$ and its composites at a melting rate of $10^{\circ} \mathrm{C} / \mathrm{min}$.

bination of reduction in the particle size and a more uniform distribution of MCB in PP matrix. An increase in the crystallinity has also been reported in PE-VMT nanocomposites. ${ }^{27}$ The fact that adding $1 \mathrm{wt} \% \mathrm{CB}$ makes the crystallinity of PP decline may arise from the agglomerations of $\mathrm{CB}$, which restrict molecular movement and hinder orderly packing of molecular segments. Lopez et al. ${ }^{28}$ has also reported a decrease in the crystallinity when adding CB in PP matrix. The same phenomenon also occurs in $\mathrm{PP} /$ $\mathrm{CaCO}_{3}$ nancomposites as well as $\mathrm{PE}$ and poly(vinylidene fluoride) nanoconposites reinforced with montmorillonite or Bentonite clays. ${ }^{4,29,30}$

It is known that the existence of inorganic particles can lead to the formation of PP crystals with less perfection and smaller size in the polymer matrix. ${ }^{31}$ When MCB and CB mix with PP, it is found that MCB can reduce the crystallite size of the matrix and narrow its distribution markedly (Figure 9). Few MCB agglomerates are observed, but a number of $\mathrm{CB}$ agglomerates exist in PP matrix. It can conclude that the small organic molecules existing on the surface of $\mathrm{CB}$ can prevent MCB from agglomerating during the mixing processing.

\section{Non-Isothermal Crystallization Kinetics}

To study kinetic parameters for non-isothermal crystallization processes, such as Ozawa equation, ${ }^{32}$ Jeziorny equation ${ }^{33}$ and Mo equation. ${ }^{34}$ In the present work, Jeziorny ${ }^{33}$ and $\mathrm{Mo}^{34}$ equations are adopted to investigate the effect of MCB on the crystallization of $\mathrm{PP}$ at a constant cooling rate.
Jeziorny Analysis of Non-Isothermal Crystallization A general form of Avrami equation ${ }^{35}$ is:

$$
1-X(t)=\exp \left(-K t^{n}\right)
$$

where $X(t)$ is the crystallinity fraction in the crystallizable material at time $t . K$ and $n$ are constants typical of a given morphology and type of nucleation.

The Avrami equation can be modified in order to describe the crystallization kinetics under non-isothermal conditions:

$$
X(t)=1-\exp \left(-Z_{\mathrm{t}} t^{n}\right)
$$

where $Z_{\mathrm{t}}$ is the growth rate constant and $n$ is the Avrami exponent. According to Jeziorny, ${ }^{33}$ because of the effect of cooling rate, $Z_{\mathrm{t}}$ must be properly corrected to obtain the kinetic crystallization at unit cooling rate, $Z_{\mathrm{c}}$ :

$$
\ln \left(Z_{\mathrm{c}}\right)=\frac{\ln \left(Z_{\mathrm{t}}\right)}{\chi}
$$

In Figure 10, there are plots of $\ln \{-\ln [1-X(t)]\}$ versus $\ln t$ for the $\mathrm{PP} / 1 \% \mathrm{MCB}$ composite (correlation coefficient $R>0.990$ ). It is found that the straight lines can be obtained at different cooling rates, however, there are slight deviations from the rectilinear relation at the end of non-isothermal crystallization process. The values of $n$ and $\ln \left(Z_{t}\right)$ are calculated from the slope and intercept of each line. It must be taken into account that in this treatment the values of $n$ and $Z_{\mathrm{t}}$ do not have the same physical meaning as in isothermal crystallization processes. Then according to eq 4 , the value of $Z_{\mathrm{c}}$ can be obtained. 


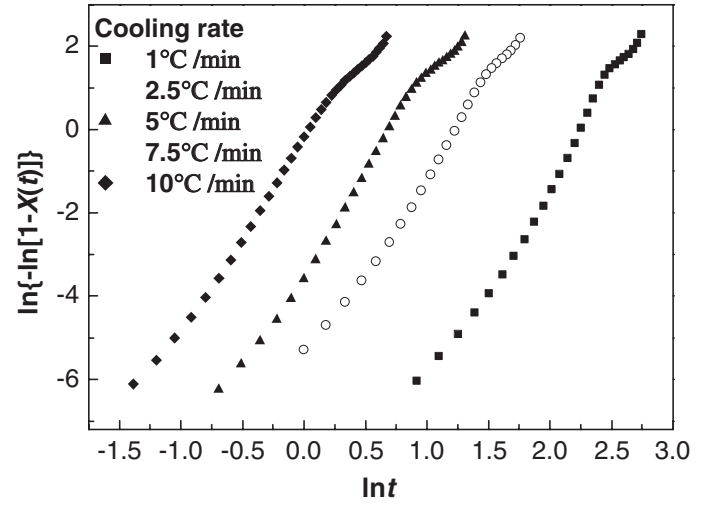

Figure 10. Plots of $\ln \{-\ln [1-X(t)\}$ vs. $\ln t$ for the PP/ $1 \% \mathrm{MCB}$ composite.

Table III. Non-isothermal crystallization kinetics parameters for pure PP and its composites

\begin{tabular}{ccccccc}
\hline \multirow{2}{*}{ Samples } & \multirow{2}{*}{$\begin{array}{c}\text { Avrami } \\
\text { parameters }\end{array}$} & \multicolumn{5}{c}{ Cooling rate $\left({ }^{\circ} \mathrm{C} / \mathrm{min}\right)$} \\
\cline { 3 - 7 } & $n$ & 4.49 & 4.46 & 4.41 & 4.43 & 4.29 \\
$\mathrm{PP}$ & $Z_{\mathrm{c}}$ & $2.99 \mathrm{e}-5$ & $6.98 \mathrm{e}-2$ & $4.24 \mathrm{e}-1$ & $6.63 \mathrm{e}-1$ & $8.48 \mathrm{e}-1$ \\
& $n$ & 4.10 & 3.96 & 4.55 & 4.00 & 4.60 \\
$\mathrm{PP} / 1 \% \mathrm{CB}$ & $Z_{\mathrm{c}}$ & $1.56 \mathrm{e}-4$ & $1.41 \mathrm{e}-1$ & $4.58 \mathrm{e}-1$ & $7.41 \mathrm{e}-1$ & $8.64 \mathrm{e}-1$ \\
& $n$ & 4.61 & 4.28 & 4.33 & 4.40 & 4.11 \\
$\mathrm{P} / 1 \% \mathrm{MCB}$ & $Z_{\mathrm{c}}$ & $3.00 \mathrm{e}-5$ & $1.19 \mathrm{e}-1$ & $5.27 \mathrm{e}-1$ & $7.58 \mathrm{e}-1$ & $9.96 \mathrm{e}-1$ \\
\hline
\end{tabular}

The crystallization rate can be evaluated according to the value of $Z_{\mathrm{c}}$, which becomes faster with increase of supercooling. The results of Table III indicate that MCB which acts as heterogeneous nuclei for the initial nucleation of PP is more efficient than CB. It also proves that the MCB accelerates the crystallization rate of $\mathrm{PP}$ faster than $\mathrm{CB}$ does.

\section{Mo's Analysis}

Mo and coworkers ${ }^{34}$ proposed a different kinetic equation by combining Ozawa and Avrami equations:

$$
\ln K+n \ln t=\ln K^{*}(T)-n \ln \chi
$$

that can be further rewritten as eq 6 :

$$
\ln \chi=\ln F(T)-b \ln t
$$

where $F(T)=\left[K^{*}(T) / K\right]^{1 / n}$, with $n$ the Avrami exponent calculated with the Ozawa method, and $b$ is the ratio between the Avrami and Ozawa exponents. $F(T)$ refers to the value of the cooling rate chosen at unit crystallization time, when the system has a defined crystallinity. According to eq 6, at a given crystallinity, the plot of $\ln \chi$ versus $\ln t$ gives a straight line with $\ln F(T)$ as the intercept and $-b$ as the slope.

As it is shown in Figure 11, at a given crystallinity, a linear relationship was observed (correlation coefficient $R>0.996$ ) and the value of $F(T)$ and $b$ are tabu-

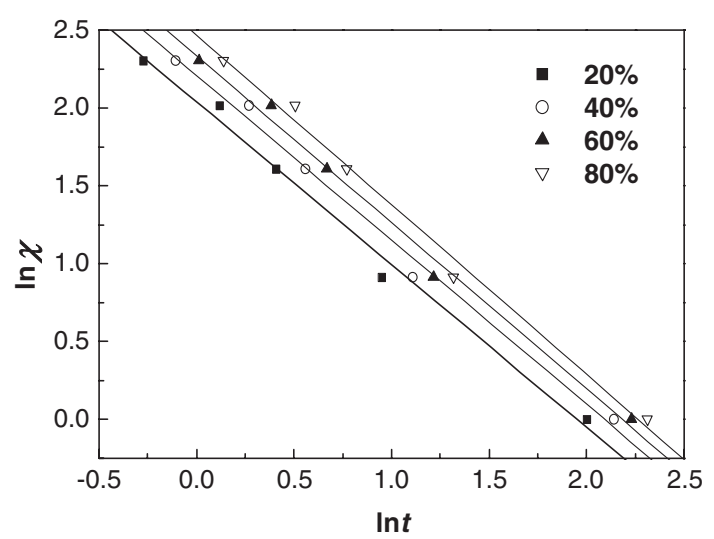

Figure 11. Plots of $\ln \chi v s . \ln t$ from Mo equation for the PP/ $1 \% \mathrm{MCB}$ composite.

Table IV. Non-isothermal crystallization parameters at different crystallinity based on Mo equation for pure PP and its composites

\begin{tabular}{cccc}
\hline Samples & $X(\%)$ & $b$ & $F(T)$ \\
\hline & 20 & 1.202 & 11.21 \\
PP & 40 & 1.204 & 13.79 \\
& 60 & 1.215 & 15.57 \\
& 80 & 1.216 & 17.7 \\
& 20 & 1.255 & 9.55 \\
PP/1\%CB & 40 & 1.255 & 11.86 \\
& 60 & 1.251 & 13.72 \\
& 80 & 1.259 & 15.86 \\
PP/1\%MCB & 20 & 1.045 & 7.69 \\
& 40 & 1.055 & 9.10 \\
& 60 & 1.069 & 10.32 \\
& 80 & 1.089 & 11.81 \\
\hline
\end{tabular}

lated in Table IV. The values of $F(T)$ improve with increase of the relative crystallinity, and those of $\mathrm{PP}$ matrix are reduced by adding MCB and $\mathrm{CB}$. Moreover, the values of $F(T)$ of the $\mathrm{PP} / 1 \% \mathrm{MCB}$ composite are the smallest at each given crystallinity. The values of $b$ are larger than 1, which mean that the Avrami exponent $n$ is always slight greater than the Ozawa exponent, $m$, as it has also been reported in literature. ${ }^{36,37}$

\section{Nucleation Activity}

An attempt is made to evaluate the results of nonisothermal crystallization with respect to nucleation activity of MCB used. Dobreva and Gutzow ${ }^{15,16,38}$ introduced a simple method for calculating the nucleation activity of foreign substrates in polymer melt. Papagergiou et al. ${ }^{5}$ and Alonso et al. ${ }^{39}$ have used this method to evaluate the nucleation activity of $\mathrm{SiO}_{2}$ and talc in PP matrix. The $\varphi$ parameter represents the ratio between the work of heterogeneous and homogeneous nucleation during the crystallization in polymer systems with different additives/substrates. If the foreign 


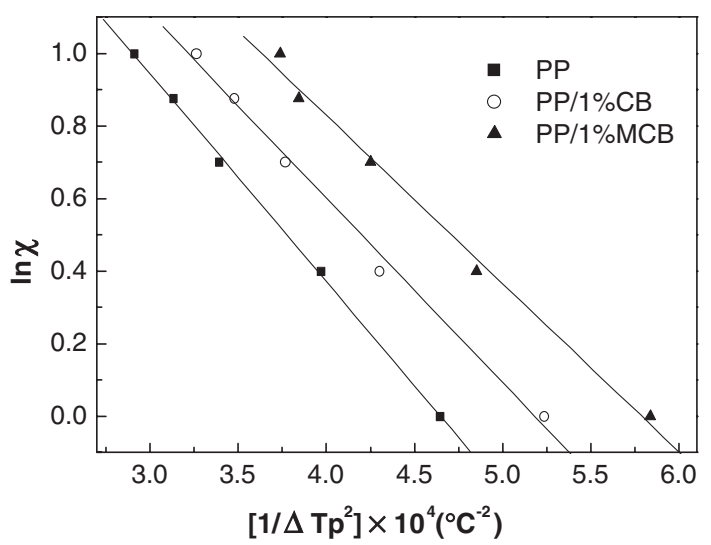

Figure 12. Plots of $\ln \chi$ vs. $1 / T_{\mathrm{p}}{ }^{2}\left(\Delta T_{\mathrm{p}}=T_{\mathrm{m}}-T_{\mathrm{p}}\right)$ for pure $\mathrm{PP}$ and its composites.

substrate is extremely active, $\varphi$ approaches 0 , while for inert particles, $\varphi$ approaches 1 .

The values of $\varphi$ are determined from Figure 12 (correlation coefficient $R>0.996$ ). From the slopes of these lines, the values of $\varphi$ for the $\mathrm{PP} / 1 \% \mathrm{CB}$ and $\mathrm{PP} / 1 \% \mathrm{MCB}$ composites are calculated, respectively. The value of $\varphi$ for the $\mathrm{PP} / 1 \% \mathrm{CB}$ composite is $0.790 \pm 0.038$ and that for the $\mathrm{PP} / 1 \% \mathrm{MCB}$ composites is $0.901 \pm 0.042$, which also point out that MCB has the higher activity for heterogeneous nucleation than $\mathrm{CB}$ does. Additional investigation is needed to clarify the role of molecules grafted on the surface of MCB on its nucleation activity. This will be explored in future publications.

\section{CONCLUSION}

Combined with the results of the TGA, FT-IR, TEM and XPS, it was demonstrated that the aggregates of $\mathrm{CB}$ were broken down and the surface of $\mathrm{CB}$ was modified during the mixing process. Both $\mathrm{CB}$ and $\mathrm{MCB}$ can provide nucleation sites to $\mathrm{PP}$, but the crystallization behavior of the $\mathrm{PP} / 1 \% \mathrm{MCB}$ composite exhibited much higher crystallization rates and narrower the crystallite size distribution than the $\mathrm{PP} / 1 \% \mathrm{CB}$ composite did. WAXD analysis showed that MCB induced $\alpha$ crystal form and there were changes in the intensities of the peaks. It was found that the Jeziorny and Mo analyses were applicable for the PP/1\%MCB and PP/1\%CB composites, which again proved that $\mathrm{MCB}$ accelerated the crystallization rate of PP faster than $\mathrm{CB}$ did. The nucleation activity evaluated during non-isothermal crystallization revealed that the nucleation activity of MCB was higher than that of $\mathrm{CB}$ at the same concentration. The resulting crystallization behavior of the PP/MCB composite such as crystallization temperature and crystallization rate will cause basic changes of mechanical properties.

\section{REFERENCES}

1. F. J. Rybuikar, J. Appl. Polym. Sci., 13, 827 (1969).

2. F. L. Binsbergen and B. G. M. Delarge, Polymer, 11, 309 (1970).

3. G. B. Gaceva, A. Janevski, and E. Mader, Polymer, 42, 4409 (2001).

4. Q. X. Zhang, Z. Z. Yu, X. L. Xie, and Y. W. Mai, Polymer, 45, 5985 (2004).

5. G. Z. Papageorgiou, D. S. Achilias, D. N. Bikiaris, and G. P. Karayannidis, Thermochim. Acta, 427, 117 (2005).

6. E. Ferrage, F. Martin, A. Boudet, S. Petit, G. Fourty, F. Jouffret, P. Micoud, P. De Parseval, S. Salvi, C. Bourgerette, J. Ferret, Y. Saint-Gerard, S. Buratto, and J. P. Fortune, J. Mater. Sci., 37, 1561 (2002).

7. J. G. Tang, Y. Wang, H. Y. Liu, and L. A. Belfiore, Polymer, 45, 2081 (2004).

8. B. Kim, S. H. Lee, D. Lee, B. Ha, J. Park, and K. Char., Ind. Eng. Chem. Res., 43, 6082 (2004).

9. M. Mucha and A. Fidrych, Polymer, 41, 4137 (2000).

10. M. Mucha and Z. Królikowski, J. Therm. Analy. Calorim., 74, 549 (2003).

11. K. Fujiki, N. Tsubokawa, and Y. Sone, Poylm. J., 22, 661 (1990).

12. N. Tsubokawa, K. Fujiki, and Y. Sone, Polym J., 20, 213 (1998).

13. S. Yoshikawa, S. Masshida, and N. Tsubokawa, J. Polym. Sci., Part A: Polym. Chem., 36, 3165 (1998).

14. J. M. Peña, N. S. Allen, M. Edge, C. M. Liauw, S. R. Hoon, B. Valange, and R. I. Cherry, Polym. Degrad. Stab., 71, 153 (2001).

15. J. M. Peña, N. S. Allen, M. Edge, C. M. Liauw, F. Santamaría, O. Noiset, and B. Valange, J. Mater. Sci., 36, 2885 (2001).

16. A. Dobreva and I. Gutzow, J. Non-Cryst. Solids, 162, 1 (1993).

17. A. Dobreva and I. Gutzow, J. Non-Cryst. Solids, 162, 13 (1993).

18. S. J. Park, K. S. Cho, and S. K. Ryu, Carbon, 41, 1437 (2003).

19. M. Mucha, J. Polym. Sci., Polym. Symp., 69, 79 (1981).

20. J. Varga, J. Thermal. Anal., 35, 1891 (1989).

21. B. Fillon, A. Thierry, J. C. Wittmann, and B. J. Lotz, J. Polym. Sci., Part B: Polym. Phys., 31, 1383 (1993).

22. G. Natta, P. Corradini, and M. Cesari, Rend. Accad. Naz. Lincei., 21, 365 (1956).

23. K. Buss, J. Kressler, and R. D. Maier, Macromolecules, 33, 8775 (2000).

24. A. T. Joners, J. M. Aiziewood, and D. R. Beckett, Makromol. Chem., 75, 134 (1964).

25. S. Piccarolo, J. Macromol. Sci. Phys., B31, 501 (1992).

26. J. X. Li, W. L. Cheung, and D. Jia, Polymer, 10, 1219 (1999).

27. S. C. Tjong and S. P. Bao, J. Polym. Sci., Part B: Polym. Phys., 43, 253 (2005).

28. M. A. López Manchado, L. Valentini, J. Biagiotti, and J. M. Kenny, Carbon, 43, 1499 (2005).

29. T. G. Gopakumar, J. A. Lee, M. Kontopoulou, and J. S. 
Parent, Polymer, 43, 5483 (2002).

30. L. Priya, J. Polym. Sci., Polym. Symp., 44, 3553 (2002).

31. K. Wang, J. S. Wu, L. Ye, and H. M. Zeng, Composites Part A, 34, 1199 (2003).

32. T. Ozawa, Polymer, 12, 150 (1971).

33. A. Jeziorny, Polymer, 19, 1142 (1978).

34. T. Liu, Z. Mo, S. Wang, and H. Zhang, Polym. Eng. Sci., 37, 568 (1997).
35. M. Avrami, J. Chem. Phys., 7, 1103 (1939).

36. L. C. Lopez and L. G. Wilkes, Polymer, 30, 882 (1989).

37. R. Zhang, H. Zheng, and X. Lou, J. Appl. Polym. Sci., 51, 51 (1994).

38. A. Dobreva, A. Stoyano A, and J. Gutzow, Appl. Polym. Symp., 48, 473 (1991).

39. M. Alonso, J. I. Velasco, and J. A. de Saja, Eur. Polym. J., 33, 255 (1997). 